\title{
MULTI-SCENARIO SIMULATION OF SUBWAY EMERGENCY EVACUATION BASED ON MULTI-AGENT
}

\author{
Wang, F. \\ Beijing Jiaotong University, Beijing 100044, China \\ E-Mail: wf_smile_ff@163.com
}

\begin{abstract}
This study introduces the mainstream theory of crowd evacuation based on multi-agent. Then a simulation model is developed based on Agent and Pathfinder to simulate the evacuation of three subway space types, including platform, station hall and stair. In addition, simulation is also carried out on the situation of the reverse running of the firefighters walking ladder and the different distribution of the crowd density. Finally, the simulation parameters are adjusted respectively to observe and compare the simulation results under different circumstances. Through the simulation of the situation of crowd evacuation under different conditions and parameters, key data such as crowd speed, number of people passing through space and remaining number, number of people passing through exit and evacuation path are recorded. These key data and the above simulation test results are vital for constructive suggestions that can be put forward for subway space design and fire control scheme.

(Received in January 2021, accepted in April 2021. This paper was with the author 2 months for 2 revisions.)
\end{abstract}

Key Words: Multi-Agent, Subway Emergency Evacuation, Simulation

\section{INTRODUCTION}

In recent years, the construction of urban rail transit in the world has entered a great leap period. Take China as an example. By December 2019, 35 cities across the country had built and opened subways, with a total mileage of 5,249.8 kilometres of urban rail transit lines. It is estimated that by 2021, the total investment in China's urban rail transit construction projects will reach 4 trillion $\mathrm{RMB}$, and the total mileage of the railway line is expected to exceed 6,000 kilometres, accounting for $15 \%$ of the world's total rail transit mileage.

The rapid development of urban rail transit has alleviated the traffic congestion in the city to a certain extent and provided the city residents with a fast and convenient way of transportation. However, some problems have also been exposed in the operation safety. Large researches have shown that subway station, as the main grass-roots unit of urban rail transit system, is a place where a large number of passengers gather, transfer and evacuate, and the passenger flow is very large. In addition, the overall structure of urban rail transit station is usually located underground, and the space is closed and relatively narrow. In case of fire, terrorist attack, large passenger flow and other emergencies, it is extremely difficult for passengers to evacuate in an emergency and it is easy to cause heavy casualties. Besides, the layout of the station and the organization of passenger flow will directly affect the evacuation difficulty of the station fire and explosion accidents. If it is not evacuated in time, it is likely to cause secondary accidents such as stampede in the station, resulting in a large number of casualties and seriously endangering the safety of life and property of passengers.

Factors like the number and location of the station facilities and equipment of urban rail transit, the design of the evacuation flow line, and the evacuation capacity of the evacuation path in the case of emergency all affect the evacuation time. When an accident occurs, different groups of people have different psychological changes. Some passengers have poor psychological endurance, and panic, fear, conformity and other psychology will occur after an accident. Additionally, some passengers will subconsciously aggravate the consequences of the accident due to the lack of emergency knowledge, and want to leave the station as soon as 
possible under the effect of fear, so they choose to move with the crowd, which leads to the concentration of passenger flow and increases the difficulty of evacuation. It is not only the panic during the accident that leads to the loss of passengers' lives, but also the failure of passengers to move quickly to a safe area within a safe time after an emergency occurs. Once an accident occurs in urban rail transit, it will seriously endanger the safety of passengers' lives and property, and also affect the public safety of the city. Every urban rail traffic accident will lead to the casualties of some passengers no matter how big or small it is. So it is necessary to study the emergency evacuation of urban rail transit and be prepared for the occurrence of emergencies.

\section{LITERATURE REVIEW}

\subsection{Urban rail transit evacuation methods}

Safety evacuation of urban rail transit is more of a decision-making method under discrete circumstances [1]. Jiang et al. studied evacuation modes in 23 scenarios by building Exodus software, compared the evacuation capacity in each group with the requirements in the current subway construction specifications, and explored and compared the effects of different possible evacuation management measures under each passenger capacity [2]. Tan et al. discussed different smoke control and evacuation modes and got the best one. Through the simulation of smoke spread on the FDS+EVAC platform, it is found that there is a linear relationship between smoke density, extinction coefficient and evacuation velocity [3]. Yang et al. found that in some cases, screen doors on the platform would affect smoke diffusion and evacuation in subway fires. Taking an actual subway station as an example, they established physical and mathematical models, and analysed the influence of four opening modes on fire smoke and evacuation by using CFD method to simulate train fire spread [4]. Lei et al. simulated the evacuation process of subway passenger. Firstly, the effects of passenger density, gate on evacuation time, exit width and passage obstacles on evacuation were carefully studied. Based on this, the Agent model under different evacuation environments was built. The research showed that passenger density was positively correlated with evacuation efficiency, but the presence of gate had little effect on evacuation time [5].

\subsection{Theory of urban rail transit evacuation}

In the case of emergency evacuation, passengers' psychology and behaviour will affect the efficiency of evacuation, and these aspects are mainly applied on the basis of data analysis [6]. Hong and $\mathrm{Xu}$ first took the safety of passengers as the starting point, analysed the impact of passengers' psychological changes, behaviours and emergency information on them in the face of emergency evacuation, and then proposed the new concept of relative density. Finally, through data analysis, with the increase of passenger flow, the evacuation time will increase accordingly. Passenger density and running speed also have obvious interaction with the length and width of the channel, so on this basis, a series of suggestions are provided for evacuation strategies in the emergency evacuation environment [7]. Wang et al. proposed a dynamic evacuation risk analysis model considering evacuees' psychological and behavioural responses based on Bayesian theory, and used event tree analysis (ETA) to simulate the subway fire scene. In this fire scenario, three control events, including fire alarm, exhaust system and evacuation route, are related to fire evacuation control, and two control events, including active escape and passive escape, are specifically defined and related to personnel characteristics. Then, the probability of the final state of each scene is calculated by Monte Carlo simulation [8]. Shiwakoti et al. discusses the train passengers may behaviour in emergency evacuation, and discusses the theory of passenger evacuation four key problems, including passive and active 
behaviour, cooperation and competition behaviour, the failure of symmetry and/exit route choice, the results of the study can help managers to formulate emergency response, to formulate appropriate strategies and training, And design effective evacuation solutions and educational activities [9].

\subsection{Model of evacuation of urban rail transit}

Simulation is one of the most effective ways to study evacuation of urban rail transit. Ma et.al. considered the evacuation crowd leaving buildings under the influence of many factors, such as emergency environment, building structure and the behaviour of the evacuees, etc., to determine the influence mechanism and extent to ensure the safe evacuation is very important, the subway station crowd evacuation is simulated, the influence parameters for the quantitative analysis, including walking speed, etc. [10]. Dai et al. introduced a visual simulation system for personnel evacuation in subway stations. According to the analysis of fire simulation values and evacuation simulation values, the data fitting algorithm was designed, and the real-time visual output problem was solved by the algorithm. The system was reviewed from the aspects of model configuration, function, establishment of model environment and visual simulation development tools [11]. Kang proposed a metro station such as emergency evacuation simulation of stochastic model, the model includes many random variables, the occupant load, for example, the initial crew load and evacuation time, the fire of random events including fire location, fire growth rate and the influence of fire smoke, can be used to determine the export path of accessibility [12]. Han et al. simulated the crowd evacuation of a subway train fire, set the density of four passengers in the train, and compared the software simulation results based on the calculation results of specifications, reflecting that the impact of passenger density on crowd evacuation is relatively reliable [13]. Yang et al. studied the fire-human model FDS+EVAC, which is a decentralized design method (DDM) applied in fire emergency evacuation simulation to reduce simulation time and cost. At present, this method is widely used in subway, mainly to study the influence of multiple factors on fire emergency evacuation [14]. In order to analyse evacuation behaviour and optimize evacuation strategy of rail transit system, Zhao et al. proposed a simulation model with evacuation agent as the centre. Firstly, an evacuation agent model is established by considering the attributes, states and decision-making behaviours of evacuees, and the operation principle and construction process of the multi-agent simulation model are discussed [15]. Cai et al. conducted a comprehensive study on fire spread and personnel evacuation in the deep-buried subway model. In the deep-buried subway model, STEPS software was used as the model to obtain personnel evacuation rules, and FDS+EVAC program was used to simulate evacuation in fire scenarios [16]. Agent method is a commonly used tool in simulation [17]. Li et al. mainly studied evacuation under fire, and Pathfinder simulation software based on Agent technology conducted simulation analysis on evacuation process of personnel [18].

\section{METHODOLOGY}

This study mainly uses Agent model to describe and simulate crowd evacuation behaviour. The research of Agent theory and technology first started from distributed artificial intelligence. In the 1980s, Agent technology gradually became independent from the field of distributed artificial intelligence and was applied more widely in fields different from distributed intelligence. The evacuation research based on multi-agent belongs to the part of multi-agent planning, and the multi-agent in Pathfinder software is an application based on multi-agent planning. The behaviour of passenger during evacuation can be simulated by setting up the multi-agent in Pathfinder. 
To explore the rules of crowd evacuation behaviour, Dirkhelbing proposed a pedestrian evacuation model, which is based on the concept of social force, which refers to the internal motivation formed for individuals when the crowd has some behaviours, like movement, rather than directly imposed by the personal environment of the pedestrians. Based on the pedestrian evacuation model in society, the driving force of pedestrians themselves, the repulsive force between people and obstacles are considered. The basic movement of pedestrians refers to the form of Newton's second law of motion. The equation of the motion process can be described as follows.

$$
m_{i} \frac{d \overrightarrow{v_{i}}}{d t}=m_{i} \frac{v_{i}^{0} \vec{e}_{i}^{0}(t)-\vec{v}_{i}(t)}{\tau_{i}}+\sum_{j(\neq i)} \overrightarrow{f_{i j}}+\sum_{W} \vec{f}_{i W}
$$

where:

$$
\begin{gathered}
\vec{f}_{i j}=\left\{A_{i} \exp \left[\left(r_{i j}-d_{i j}\right) / B_{i}\right]+k g\left(r_{i j}-d_{i j}\right)\right\} \vec{n}_{i j}+k g\left(r_{i j}-d_{i j}\right) \Delta v_{i j}^{t} \vec{t}_{i j} \\
\vec{f}_{i W}=\left\{A_{i} \exp \left[\left(r_{i}-d_{i W}\right) / B_{i}\right]+k g\left(r_{i}-d_{i j}\right)\right\} \vec{n}_{i w}+k g\left(r_{i}-d_{i w}\right)\left(\vec{v}_{i} \cdot \vec{t}_{i w}\right) \vec{t}_{i W}
\end{gathered}
$$

where $m_{i}$ is the mass of $v, v_{i}^{0}$ is the expected speed of pedestrian, $\vec{e}_{i}(t)$ is the expected direction of pedestrian, $\vec{v}_{i}(t)$ is the actual speed of pedestrian, $\tau_{i}$ is relaxation time, which means the change of actual speed of pedestrian, while the speed of pedestrian is affected by $\vec{f}_{i j}$ and $\vec{f}_{i W}$. $\vec{f}_{i j}$ means the effect of forces on pedestrians caused by neighbours, $\vec{f}_{i W}$ means the effect of forces on pedestrians caused by obstacle. $r_{i j}$ indicates the sum of the dimensions between two persons, $d_{i j}$ indicates the sum of the distance between two persons.

The study adopts Pathfinder algorithm as crowd evacuation algorithm, which mainly contains two aspects, one is the setting of evacuation environment, the other is the setting of evacuation personnel behaviour. Through the setting of two aspects, the multi-agent can judge the evacuation path, and then calculate the evacuation time and the possible situation during evacuation, such as crowding, etc. Pathfinder belongs to a class of BIM (Building Information Model) software. However, Pathfinder is not similar to 3ds Max, Revit and other software that is inclined to architectural design and architectural performance. The setting of evacuation environmental information of Pathfinder serves the evacuation behaviour of crowd, so emphasis is placed on evacuable area, evacuation exit, floor passageway, obstacles, etc., but does not devote to the concrete representation of evacuation environment. Another main content of Pathfinder is the behaviour settings of evacuators, including the evacuation speed distribution type of the crowd, such as normal distribution, uniform and distribution, constant, etc., shoulder width, whether to use equipment. Through the cooperation of the two functions, the simulation crowd evacuation path and time are calculated.

Pathfinder software has a good simulation of the crowd evacuation scene, for the crowd evacuation theory verification, experiment, simulation provides a good tool, whether in academic or fire practice, teaching has a very good application.

In Pathfinder, evacuation model using steering model because the steering mode is closer to the behaviour of the crowd emergency evacuation. The movement of the multi-intelligent body in the Steering mode was consistent with the following algorithm.

(1) Expected velocity and acceleration at the starting position is as follows.

$$
\begin{gathered}
V_{1}=V_{\text {max }} \times \frac{0.85 k}{1.19} \\
a_{\text {max }}=\frac{V_{\text {max }}}{t_{\text {accel }}}
\end{gathered}
$$

where, $v_{1}$ represents the expected velocity of the starting position, $v_{\max }$ represents the maximum speed of the multi-agent body, $k$ is the evacuation impact factor, which is determined by the 
evacuation environment, which is different in the plane and stairs. $a_{\max }$ is the maximum acceleration, $t_{\text {accel }}$ represents the acceleration time.

(2) Determine evacuation direction.

$$
C_{\text {seek }}=\frac{\theta_{\mathrm{t}}}{2 \pi}
$$

where $C_{\text {seek }}$ means direction weight, $\theta_{t}$ means the angle between the seek curve and the velocity direction of the optimal evacuation curve.

(3) Expected speed and acceleration when moving.

$$
\begin{gathered}
\left|\overrightarrow{v_{1}}\right|=\left\{\begin{array}{l}
0\left(d_{\max } \leq d_{\text {stop }}\right) \\
v_{1}\left(d_{\max }>d_{\text {stop }}\right)
\end{array}\right. \\
\overrightarrow{v_{2}}=\left|\overrightarrow{v_{1}}\right| \overrightarrow{d_{1}}
\end{gathered}
$$

where $\overrightarrow{v_{1}}$ means the vector speed of the current moving direction, $d_{\text {max }}$ means maximum walking distance in this direction, $d_{\text {stop }}$ is the shortest acceleration distance in this direction, $\overrightarrow{v_{2}}$ is the velocity vector in the direction of movement with the smallest weight, $\overrightarrow{d_{1}}$ is the evacuation vector direction in that direction, $\overrightarrow{a_{1}}$ is the vector acceleration in that direction.

(4) The vector formula of the velocity and position to arrive at position.

$$
\begin{aligned}
& \overrightarrow{v_{3}}=\overrightarrow{v_{2}}+\overrightarrow{a_{1}} \Delta t \\
& \overrightarrow{q_{2}}=\overrightarrow{q_{1}}+\overrightarrow{v_{2}} \Delta t
\end{aligned}
$$

where $\overrightarrow{v_{3}}$ is the vector velocity at arrival, $\overrightarrow{q_{1}}$ and $\overrightarrow{q_{2}}$ are the arrival point and the current location respectively, $\Delta t$ is the interval time.

\section{SIMULATION MODEL AND RESULTS}

This study will study the three kinds of space, including platform, station hall and walking ladder. Evacuation simulation in the three scenarios all follows the simulation steps as shown in the simulation roadmap.

\subsection{Platform simulation}

Platform is the connecting space between passengers and subway cars. After a fire breaks out on the platform, passengers should drive into the subway cars that have not stopped on the platform in accordance with the evacuation requirements, and go directly to the next station without stopping at the fire station. Therefore, when a fire occurs, only the crowd evacuation behaviour on the platform can be considered. Taking the island platform as an example, this study discusses the simulation of crowd evacuation after a fire on the platform. The Pathfinder model of island platform evacuation is established. The platform model is divided into two layers. The first layer is the platform with a plane area of $120 \mathrm{~m} \times 14 \mathrm{~m}$ and a height of $6 \mathrm{~m}$. The area of the second floor is the same as that of the first floor, also $120 \mathrm{~m} \times 14 \mathrm{~m}$. There are two steps between the first floor and the second floor, and the width of the stairs is $4 \mathrm{~m}$. Evacuate pedestrians from the platform of the first floor through the pedestrian ladder, to the safety exit between the two sides of the second floor, the length of the safety exit $10 \mathrm{~m}$. On the first floor, 200 evacuees are randomly distributed. The model is shown below. 


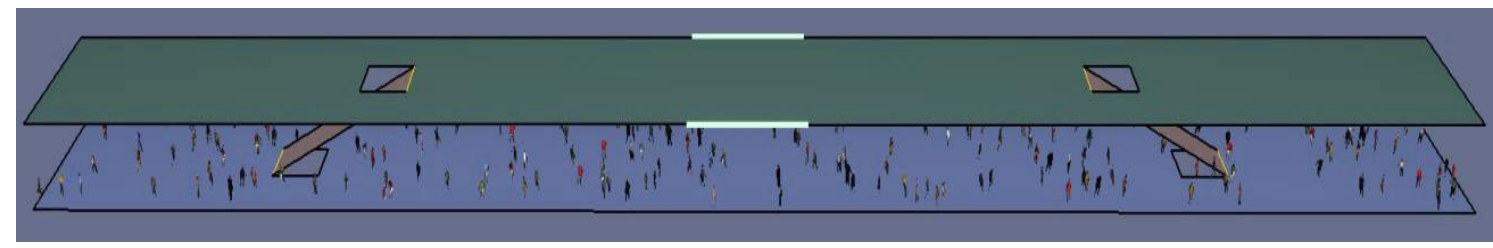

Figure 1: Platform evacuation model.

The simulation results are as follows through computer calculation.

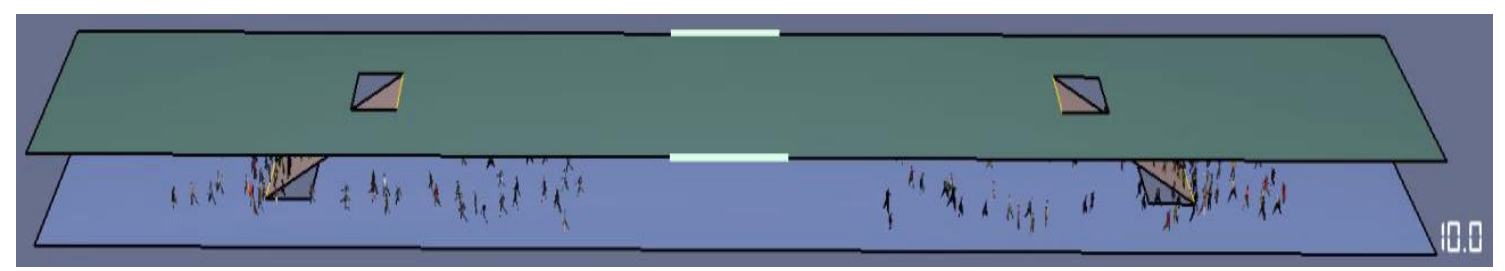

Figure 2: Platform evacuation at $T=10 \mathrm{~s}$.

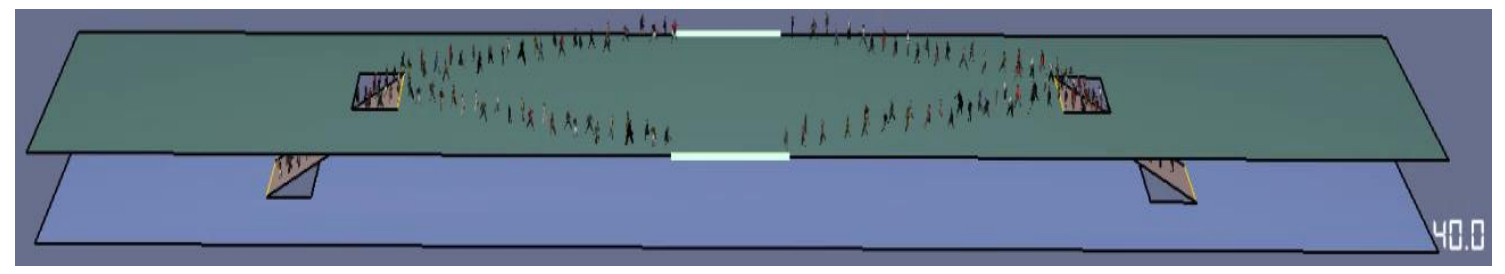

Figure 3: Platform evacuation at $T=40 \mathrm{~s}$.

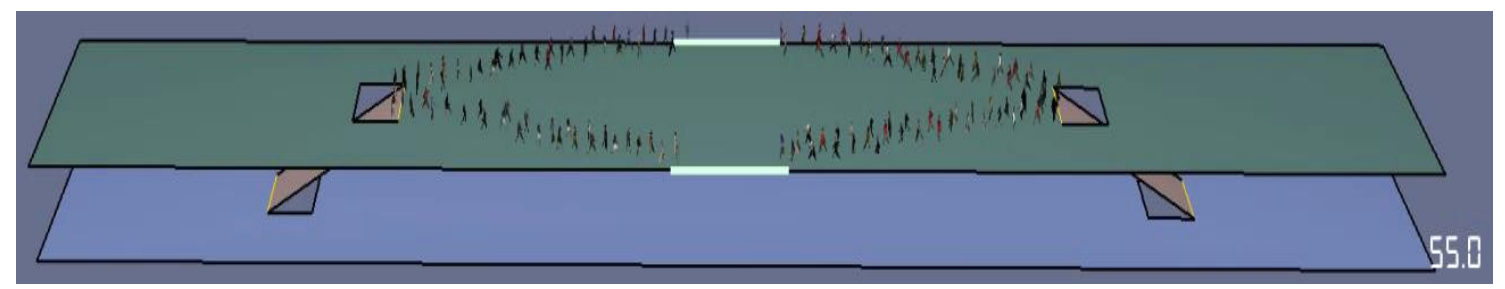

Figure 4: Platform evacuation at $T=55 \mathrm{~s}$.

The simulation results show that evacuees have left the middle area of the first floor at the $10^{\text {th }}$ second, and all left the platform on the first floor at the $40^{\text {th }}$ second. Besides, evacuees have left the walking ladder between the first and second floors at 55 seconds, and the pedestrian evacuation was basically completed at the $75^{\text {th }}$ second.

Additionally, the simulation results show that the evacuation is orderly and there is no crowding. The evacuation route is shown below.

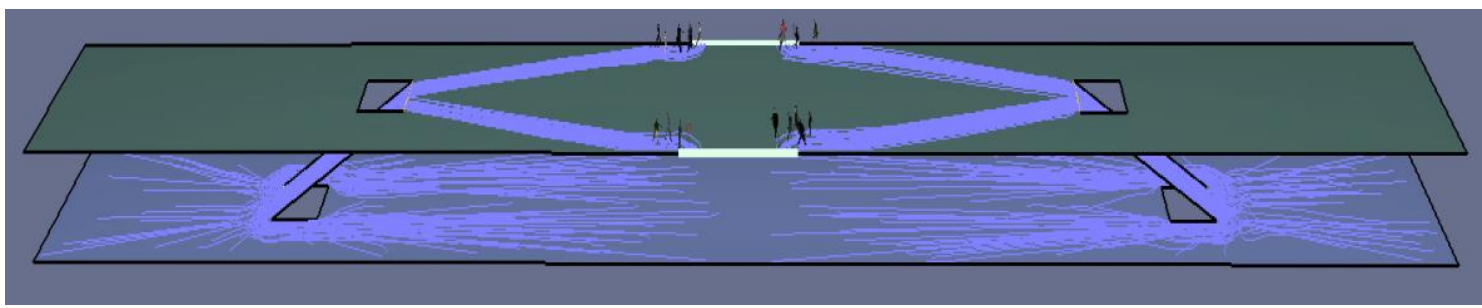

Figure 6: Platform evacuation situation-evacuation route.

The evacuation route shows that the evacuation route is centralized and orderly after the pedestrians enter the first floor through the walking ladder, indicating that the evacuation is in good condition after the evacuees enter the first floor. Stair 01 peaks between seconds 18 and 38 , with a peak number of $40-45$ people per second. Stair 02 peaks in $30-32$ seconds with 59 
people. This lies the fact that the initial location of the crowd on the platform floor minus 1 is not randomly distributed, and the relatively small number of pedestrians approaching Stair 01 .

\subsection{Station hall evacuation simulation}

Station hall is an important environment for subway station to connect with external space, and it is also a necessary space for crowd evacuation. According to their own objective conditions and carrying capacity of different stations and halls, their planning and equipment layout are different. There are ticket Windows, or called ticket machines, security inspection equipment, passenger service centres, etc. Generally speaking, inbound and outbound passengers are split at station hall to ensure the speed of passenger flow.

Passengers on two or more interchange lines need to pass the interchange hall and transfer to another platform according to the guidance. The evacuation model of the station hall is studied and established in this study. The area of the station hall is $40 \mathrm{~m} \times 30 \mathrm{~m}$, and the station hall has three doors. Door 01 is the exit, Door 02 is the entrance of people who have been checked, Door 03 is the connection between the station hall and the passage. There is a ticket selling area in the space, and the evacuees cannot pass through the ticket selling area. The diversion line is the equipment to separate the inbound and outbound passengers, and the evacuees need to bypass the diversion line to the exit Door 01. Door 03 is the connecting port between the station hall and the passageway. When a fire breaks out, there are people in the passageway entering the station hall from Door 03. The model is shown below.

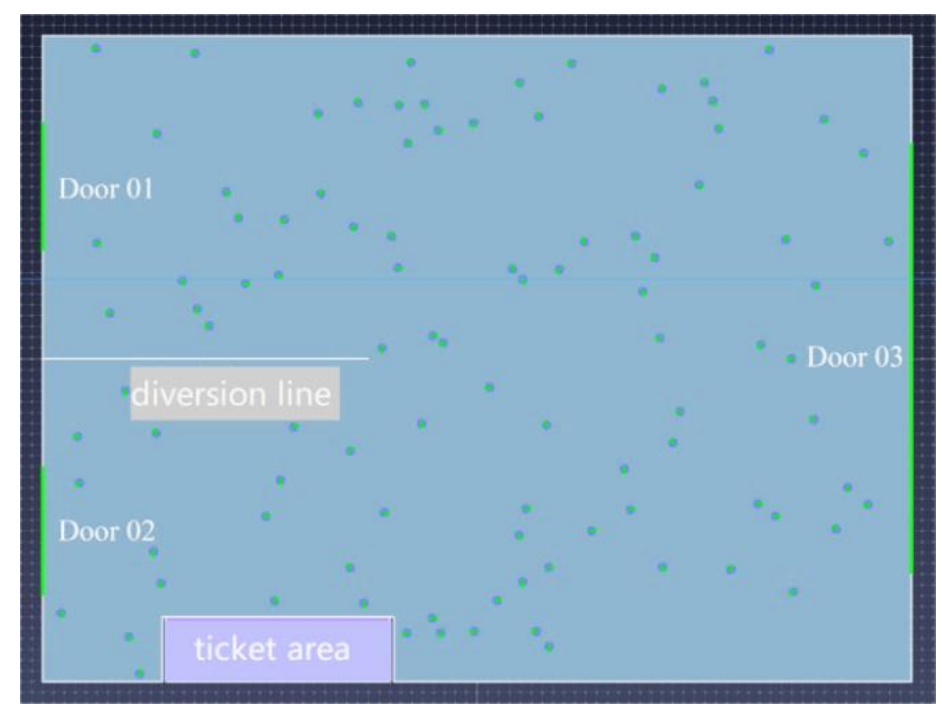

Figure 7: Evacuation simulation model of exhibition hall.

Suppose there were 100 passengers in the station when the fire broke out. When the evacuation alarm sounded, the crowd in the station hall began to evacuate. At the same time, some passengers poured into the station hall through Door 03 and escaped to Door 01. At the $3^{\text {rd }}$ minute, the last passenger was evacuated from Door 03. Corresponding table function at Door 03 is as follows.

Table I: Crowd rate table function at Door 03.

\begin{tabular}{|c|c|c|c|c|c|c|c|c|c|}
\hline Time (s) & 0 & 3 & 20 & 40 & 60 & 80 & 120 & 150 & 180 \\
\hline Flow rate (pers/s) & 0 & 1 & 5 & 8 & 10 & 8 & 5 & 3 & 0 \\
\hline
\end{tabular}

Through the calculation and simulation of Pathfinder, the evacuation of the crowd was completed in 215 seconds after the start of evacuation. Below is the evacuation process. 

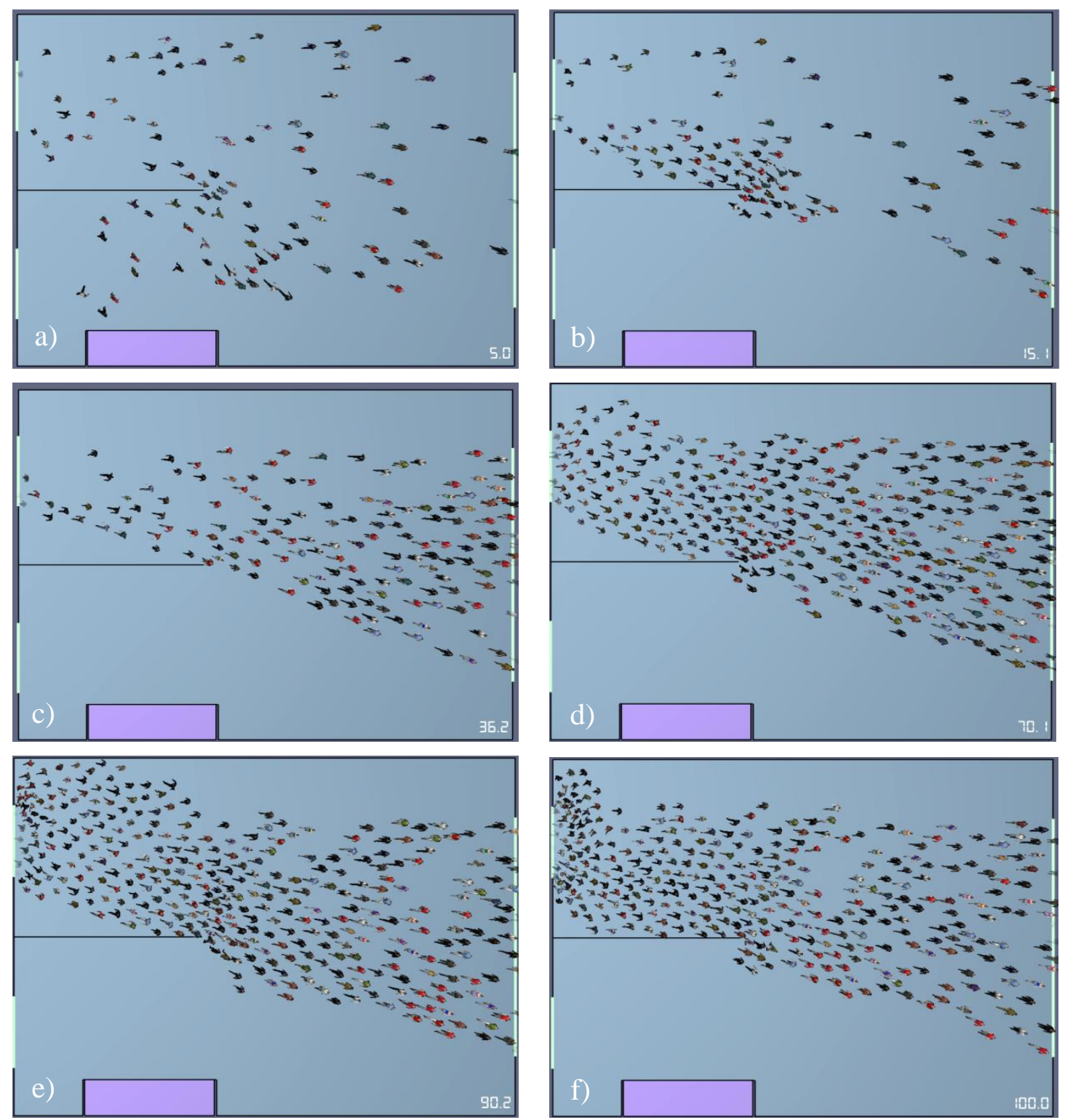

Figure 8: Evacuation chart (top view) at: a) $T=5$ seconds, b) $T=15$ seconds, c) $T=36$ seconds, d) $T=70$ seconds, e) $T=90$ seconds, f) $T=100$ seconds.

At the $36^{\text {th }}$ second, 100 people originally in the station hall had been completely evacuated, and all the people in the station hall were pedestrians newly entering the area from Door 03. At this time, the number of people in the station hall was small, the evacuation crowd formed orderly formation, and there was no crowding in the evacuation. Although the evacuation time of different scenarios is very close, due to the limited width of doors in some scenario models, a large number of evacuees are gathered outside the door, which is easy to cause panic among evacuees and further cause other accidents. While in some cases, evacuations appear to be proceeding in an orderly manner.

\subsection{Stair evacuation simulation}

Stairs are passageways linking floors of different heights, which play a very important role in crowd evacuation. Evacuation simulation of the stair is helpful to judge whether the stair affects the evacuation and the critical point of the number of passengers in the safe evacuation.

A stair evacuation model was established in this study. In the model, the stair was set to connect three planes, the first floor was $0 \mathrm{~m}$ high, the second floor was $4 \mathrm{~m}$ high, and the third 
floor was $8 \mathrm{~m}$ high. There were stairs between the first and second floors, and between the second and third floors, and the width of the stairs was $1.5 \mathrm{~m}$. The evacuation crowd enters the model area through Exit A, Exit B and Exit $\mathrm{C}$ and then evacuates to Exit D. The rate of crowd output from Exit A, B and C is 1 pers/s. After 1 minute, there will be no crowd entering the model at Exit A, B and C.

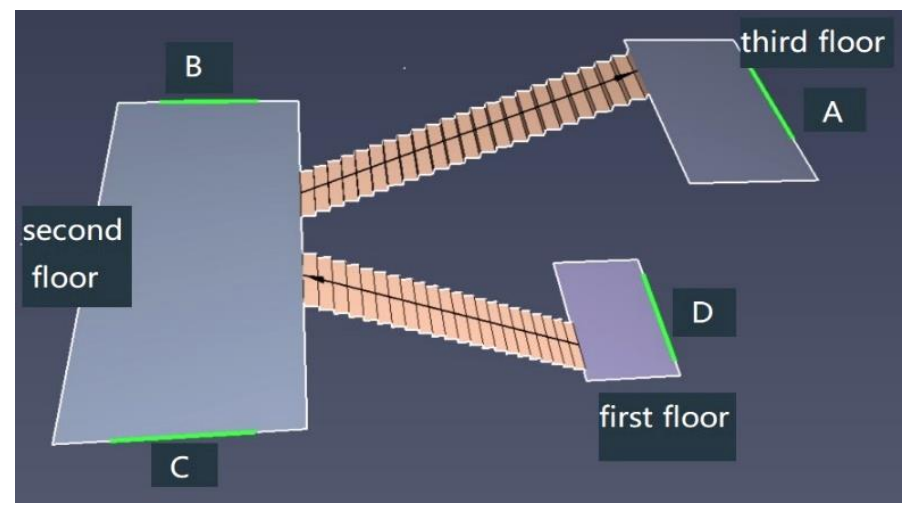

Figure 9: Pathfinder model description.

The simulation results are as follows.
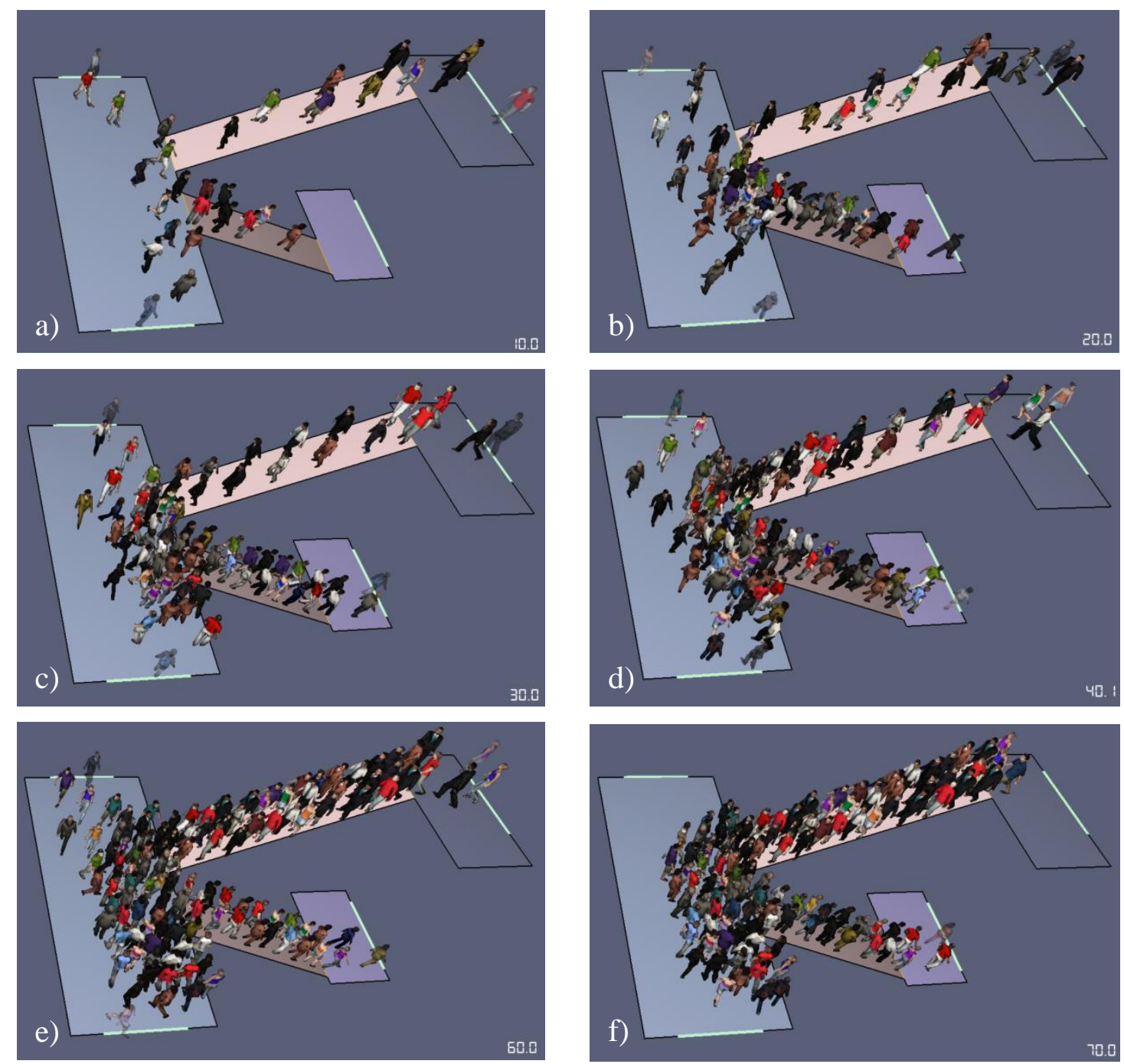

Figure 10: Evacuation simulation of walking ladder (perspective view) at: a) $T=10$ seconds, b) $T=20$ seconds, c) $T=30$ seconds, d) $T=40$ seconds, e) $T=60$ seconds, f) $T=70$ seconds. 
Figures illustrate that the evacuees were evacuated in an orderly manner at the $10^{\text {th }}$ second, the evacuees on the third floor had not reached the second time, and the people at the front of the evacuees on the second floor had not reached the exit. At the $20^{\text {th }}$ second, it can be seen that the stair between the first and second floor is already crowded. Pedestrians are two side by side through the stair basically, and some people have begun to gather at the corner of the second floor stair. Stairs between the second and third floor were evacuated in an orderly manner. At the $30^{\text {th }}$ second, the first and second floors are still crowded, and the status of the staircase is maintained at the $20^{\text {th }}$ second. Stair between the second and third floor has been deliberately staggered shoulder evacuation, this evacuation method can make the limited stair space can still be evacuated at a faster speed. At this time, more people have gathered on the second floor. At the $40^{\text {th }}$ second, the staircase between the second and third floor had begun to gather some evacuees, and the crowd gathering at the corner of the staircase had begun to affect the evacuation of the people on the staircase between the second and third floor. At 60 seconds, both stairs are already filled with evacuees, and the second floor also has the highest crowd density. At the $70^{\text {th }}$ second, Exit A, B and C no longer have pedestrian output, and the evacuation space is still very crowded. At the 100th second, the crowd at the corner of the stair on the second floor had decreased, while more people were still gathered on the two stairs. Within 130 seconds, the crowd of the stair between the second and third floors had been basically evacuated, a small number of people gathered at the corner of the stair, and the stair between the first and second floors was still crowded. At 160 seconds, the evacuation is almost complete.

\section{CONCLUSION}

The study introduces the mainstream theory of crowd evacuation with multi-agent, and lay focus on the theory of crowd social force, then develop simulation based on Pathfinder, which is an evacuation simulation software developed based on crowd social force. Besides the illustration of crowd evacuation theory, the paper also uses the existing statistical data of crowd evacuation behaviour to assist in setting the simulation scene. The simulation road map described in this study shows three spaces at station, including platform, station hall and walking ladder, and also the simulation steps and routes in the two situations of reverse walking ladder and crowd density are showed in the simulation. Additionally, evacuation simulation in five scenarios all follows the simulation steps as shown in the simulation road map.

Evacuation simulation is carried out for three subway space types, including platform, station hall and stairs. In addition, simulation is carried out on the situation of the reverse running of the walking ladder and the different distribution of the crowd density. The simulation parameters are adjusted respectively to observe and compare the simulation results under different circumstances through the simulation of the above scenarios. Besides, situation of crowd evacuation under different conditions and parameters are observed, and key data such as crowd speed, number of people passing through space and remaining number, number of people passing through exit and evacuation path are recorded in the process of evacuation. Through the above simulation test results, constructive suggestions can be put forward for subway space design and fire control scheme.

\section{REFERENCES}

[1] Gajsek, B.; Marolt, J.; Rupnik, B.; Lerher, T.; Sternad, M. (2019). Using maturity model and discrete-event simulation for Industry 4.0 implementation, International Journal of Simulation Modelling, Vol. 18, No. 3, 488-499, doi:10.2507/IJSIMM18(3)489

[2] Jiang, C. S.; Ling, Y.; Hu, C.; Yang, Z.; Ding, H.; Chow, W. K. (2009). Numerical simulation of emergency evacuation of a subway station: A case study in Beijing, Architectural Science Review, Vol. 52, No. 3, 183-193, doi:10.3763/asre.2008.0047 
[3] Tan, J.; Wang, T.; Chen, Y.; Bai, G. (2009). Safety evacuation measures in urban subway fire, 2009 Second International Conference on Intelligent Computation Technology and Automation, 422-425, doi:10.1109/ICICTA.2009.817

[4] Yang, J.-T.; Yang, Y.; Wang, H.-L.; Shi, L. (2011). Effect of the open ways of screen doors on fire smoke in a subway platform, Procedia Engineering, Vol. 11, 416-423, doi:10.1016/ j.proeng.2011.04.677

[5] Lei, W.; Li, A.; Ran, G.; Hao, X.; Deng, B. (2012). Simulation of pedestrian crowds' evacuation in a huge transit terminal subway station, Physica A: Statistical Mechanics and its Applications, Vol. 391, No. 22, doi:10.1016/j.physa.2012.06.033

[6] Kim, B. S.; Kim, T. G. (2019). Cooperation of simulation and data model for performance analysis of complex systems, International Journal of Simulation Modelling, Vol. 18, No. 4, 608-619, doi:10.2507/IJSIMM18(4)491

[7] Hong, L.; Xu, R. H. (2011). Analysis on game behaviors of passengers in emergency evacuation in subway station, Applied Mechanics and Materials, Vol. 97-98, 576-582, doi:10.4028/ www.scientific.net/AMM.97-98.576

[8] Wang, J.; Yan, W.; Xu, H.; Zhi, Y.; Wang, Z.; Jiang, J. (2018). Investigation of the probability of a safe evacuation to succeed in subway fire emergencies based on Bayesian theory, KSCE Journal of Civil Engineering, Vol. 22, No. 3, 877-886, doi:10.1007/s12205-018-0620-7

[9] Shiwakoti, N.; Tay, R.; Stasinopoulos, P.; Woolley, P. J. (2017). Likely behaviours of passengers under emergency evacuation in train station, Safety Science, Vol. 91, 40-48, doi:10.1016/ j.ssci.2016.07.017

[10] Ma, J. C.; Zhou, X. Y.; Li, J. (2009). Application of computer simulation method to parameter influence study of crowd evacuation, Journal of Natural Disasters, Vol. 18, No. 6, 154-159

[11] Dai, B.; Wang, T.; Qin, Y. (2009). Subway station evacuation simulation system, Proceedings of the 2009 International Conference on Measuring Technology \& Mechatronics Automation, 396399, doi:10.1109/icmtma.2009.37

[12] Kang, K. (2011). A stochastic evacuation model for fire life safety assessment in transportation system, Peacock, R.; Kuligowski, E.; Averill, J. (Eds.), Pedestrian and Evacuation Dynamics, Springer, Boston, 307-315, doi:10.1007/978-1-4419-9725-8_28

[13] Han, X.; Ma, J. N.; Cong, B. H. (2012). Simulation analysis on crowd evacuation of the subway train fire, Advanced Materials Research, Vol. 424-425, 1215-1219, doi: 10.4028/ www.scientific.net/AMR.424-425.1215

[14] Yang, P.; Li, C.; Chen, D. (2013). Fire emergency evacuation simulation based on integrated fireevacuation model with discrete design method, Advances in Engineering Software, Vol. 65, 101111, doi:10.1016/j.advengsoft.2013.06.007

[15] Zhao, D. F.; Zhang, X. L.; Su, Y. (2014). Reliability analysis of relevant random variables in pedestrian evacuation study in underground transportation hub, Advanced Materials Research, Vol. 1020, 741-746, doi:10.4028/www.scientific.net/AMR.1020.741

[16] Cai, Y.; Lin, Z.-Y.; Mao, J.; Bai, G.; Hu, J.-W. (2016). Study on law of personnel evacuation in deep buried metro station based on the characteristics of fire smoke spreading, Procedia Engineering, Vol. 135, 544-550, doi:10.1016/j.proeng.2016.01.098

[17] Fragapane, G. I.; Zhang, C.; Sgarbossa, F.; Strandhagen, J. O. (2019). An agent-based simulation approach to model hospital logistics, International Journal of Simulation Modelling, Vol. 18, No. 4, 654-665, doi:10.2507/IJSIMM18(4)497

[18] Li, Z.-Y.; Tang, M.; Liang, D.; Zhao, Z. (2016). Numerical simulation of evacuation in a subway station, Procedia Engineering, Vol. 135, 616-621, doi:10.1016/j.proeng.2016.01.126 